\section{The official's book of risky business}

\section{Alastair Hay}

\author{
Major Technological Risk: An Assessment \\ of Industrial Disasters. By Patrick \\ Lagadec. Pp.536. ISBN 0-08-028913-4. \\ (Pergamon: 1982.) \$60,£30.
}

ONE way of summarizing the message of Paul Lagadec's book would be "High technology versus democracy"'. The result of a doctoral thesis in political science, Lagadec's Major Technological Risk is a panoramic look at the problems posed by high technology. As befits a thesis on this subject, it is the politics of risk which interest Lagadec rather than the idea of finding a "technological fix" for every conceivable accident.

The answer to many of the problems involved in assessing risk is information, says Lagadec. And the most important element in this is informing the public. Risk assessment is about probabilities and uncertainties. These ideas, he points out, may be understandable to the expert; they are not so to the average citizen who is often running the risk. Lagadec believes that the public wants this information, but that industry and governments may not always be too keen to provide it.

To illustrate his theme the author chooses five seminal accidents of the last decade: the chemical explosion at Flixborough (United Kingdom); the release of dioxin at Seveso (Italy); the failure of the nuclear reactor at Three Mile Island (United States); the discharge of oil from the wrecked tanker Amoco Cadiz (France); and the release of chlorine from tanks on a derailed train in the centre of Toronto (Canada). In all of these cases technical failure was the direct cause of the accident, although the post-mortems of the events showed that inadequate legislation was a contributing factor in some, and in others communication between emergency services was so poor that this had its effect on the outcome.

It is the aftermath of these accidents which most concerns Lagadec. Mapping the extent of the damage was relatively easy in the case of Flixborough and the Amoco Cadiz; the trail of destruction was evident from the blast-damaged buildings and oilpolluted beaches. Apportioning blame in both cases was less easy, and Lagadec argues that the official Commission of Enquiry into the Flixborough accident was too lenient in this area.

The cases of Seveso and Three Mile Island illustrate points different from those raised by Flixborough. Assessing the damage was much more difficult; the danger was not visible. At Seveso it took time to find the extent of dioxin pollution - the delay in doing this resulted in people living in a highly polluted area for two weeks, before they were told to leave their homes. At Three Mile Island the release of radiation caused panic amongst the local populace, and an estimated 200,000 people left the area of their own volition. They were encouraged to take this step by the ineptitude of the government, regulatory authorities and company officials who issued often contradictory information.

At Seveso, poor communication between officials and the residents rapidly led to disillusionment with the health surveillance programme. The public began to distrust officials. Similar sentiments were evident in the wake of the Three Mile Island debacle. According to Lagadec the consequences of this public distrust are serious. If it persists, he argues, it will become even more difficult to contain disasters. His remedy is for officialdom to take the public into its confidence. By so doing the average citizen may at least be convinced that everything possible is being done to ameliorate the effects of the disaster.

As for the release of chlorine in Toronto, this is an example of officials and emergency services working well. The evacuation of over 250,000 people was achieved relatively painlessly. There are lessons here for regulatory authorities, Lagadec says.

This book is addressed to those officials responsible for dealing with potential dis-

\section{Art of gel cookery}

\section{E.G. Richards}

Gel Electrophoresis of Nucleic Acids: $A$ Practical Approach. Edited by D. Rickwood and B.D. Hames. Pp.242. Pbk ISBN 0-904-14724-X. (IRL Press: 1982.) $£ 8.50, \$ 18$.

LIKE a soufflé dish, gel electrophoresis requires no great knowledge of theory to achieve admirable results but it does require a certain concentrated attention to practical detail. This volume provides such detail in abundance for the application of gel electrophoresis to nucleic acids. These details are described by ten authors in six chapters which cover more ground than the title of the book might suggest, including as they do, articles on the sequencing of both DNA and RNA and on the electrophoresis of nucleoproteins. Detailed descriptions of apparatus and protocols for their use are provided for the analysis of RNA or DNA preparations in agarose and polyacrylamide gels, gradient gels, two dimensional gels, preparative gels and most of the other available methods that are applicable to nucleic acids.

Theory, even at the level of the application of Ohm's law, is virtually absent. One consequence of this is that the naive reader has no way of knowing whether he aster. It might also be aimed at an informed public - the text, if somewhat diffuse, is not too difficult for the lay reader. As for workers in industry, they do not fit into Lagadec's scheme of things. He argues that they will benefit indirectly from more public accountability. Pollution controls such as Clean Air Acts do, of course, benefit everybody but workers in industry have their own particular problems, made all the more difficult by inadequate information - their requirements are more direct than the prescriptions offered in this book.

The book does suffer from being too long and is in parts repetitive. The index a list of accidents - is inadequate for the text, and led to considerable frustration on the part of this reader. More specifically, with regard to the cause of the Seveso accident the author is mistaken in saying that this was probably attributable to a reduction in the solvent in the 2,4,5-trichlorophenol reactor; localized heating in the top few centimetres of the reaction mix was almost certainly to blame. These criticisms, however, do not detract from the value of this book. Its message is important, and those interested in risk would do well to read it.

Alastair Hay is a Lecturer in the Department of Chemical Pathology at the University of Leeds, and author of The Chemical Scythe: Lessons of $2,4,5-T$ and Dioxin, published late last year by Plenum Press.

will stumble into a pitfall if he departs ever so slightly from the received instructions. He may even conclude that all procedures have been carefully planned to give optimal results. But every cook has his favourite recipes and several of the authors admit that theirs was arrived at by a process of trial and error. Even if the reader sticks to the letter of the law strange- results will sometimes appear as disaster strikes. The explanations of some of the more controllable of these are described; others which still defy explanation are not mentioned.

The scanning of gels to obtain an estimate of the amount of nucleic acid in a zone is mentioned several times. It is a pity that an additional chapter was not included which described in detail how this might be accomplished and some of the attendant difficulties, for the optics used in some commercially available gel scanners are barely equal to the task.

Workers interested in the theory of gel electrophoresis or in the history of its application to nucleic acids had better look elsewhere, but this laboratory manual will be found useful if you want to set up experiments. The list of worldwide firms which supply equipment and materials, included at the end, will help you too.

E.G. Richards is a Senior Lecturer in the Department of Biophysics, King's College, University of London. 